\title{
Comunicação e educação: passagens e deslocamentos
}

Adilson Citelli ${ }^{1}$

É professor titular do Departamento de Comunicaçoes e Artes da ECA/USP, onde ministra cursos de graduação e pós-graduação. Orienta dissertações e teses nas áreas de Comunicação e Linguagem, com ênfase nas subáreas comunicação/educação, comunicação/linguagem. É co-editor da revista Comunicação \& Educação, bem como pesquisador $1 C$ do CNPq. E-mail: citelli@uol.com.br

Resumo: Em sua parte inicial, esta apresentação procura refletir acerca dos mecanismos que inter-relacionam comunicação, educação e cotidiano. Para tanto, avoca os conceitos de não-lugar, deslocamento e resíduo, mostrando-os como instâncias que contribuem para melhor entender determinados processos de complementaridade, oposição e tensão colocados entre as salas de aula, os media e o saber comum.

Palavras-chave: comunicação, educação, cotidiano, resíduo, deslocamento.
Abstract: In its initial part, this introductory article makes reflections on the mechanisms that interrelate communication, education and the everyday life. For that, it highlights the concepts of no place, displacement and residue showing them as instances that contribute to better understand specific processes of complementarity, opposition and tension set between classrooms, media and common knowledge.

Keywords: communication, education, daily life, residue, displacement.

Os circuitos educacionais encontram quadro singular quando remetidos aos processos e sistemas comunicativos. Para evidenciar uma destas questões próprias às dinâmicas societárias fortemente influenciadas pelas estratégias comunicacionais, seria suficiente ponderar com as temáticas do deslocamento dos/nos espaços. Ainda que o problema não seja novo, afinal, a partir do momento em que os mares conheceram venturosos tipos como Ulisses ou Vasco da Gama, o desbordar, as viagens, as migrações, ganharam densidade e volume, alcançando, no mundo contemporâneo, outras formas de circulação patrocinadas pelos aportes telemáticos. Em quadro histórico que parece não se referir mais à noção de mapa - algo fixo e bem delimitado -, mas de topografia, cartas sem o rigor das linearidades, com seus traçados oscilantes entre píncaros, vales, planícies e depressões, apreender a ideia dos deslocamentos que alcançam amplamente a sociedade e a cultura impõe-se de modo decisivo. A menos que, como Jesús Martín-Barbero, falássemos da existência de mapas noturnos, guias, e, como se percebe, pouco confiáveis

1. É autor de inúmeros artigos e livros; dentre estes se destacam: Linguagem e persuasão (Ática, 1994); Comunicação e educação: a linguagem em movimento (SENAC, 2000); Palavras, meios de comunicação e educação (Cortez, 2006). 
para conduzir de modo seguro e pleno de certeza os viajores que transitam, em nosso tempo, pelos universos da cultura e do conhecimento.

E não se trata, aqui, de reconhecer a evidência, mas de tentar entender o problema no interior de manifestações que impactam na vida das pessoas, das instituições, das organizações. Abstrair esse trânsito contínuo e fixar o conceito de mapa pode significar a perda de uma referência central para se pensar em vários dos fenômenos que nos circundam: formação da sociabilidade, da subjetividade; modos de configurar o capital; os andamentos das mercadorias; estratégias de produção e circulação do conhecimento. Enfim, as forças que arranjam a chamada alta modernidade, em suas proposições objetivas e subjetivas, conquanto não se resumam ou se esgotem no tema do deslocamento, deste são profundamente tributárias.

Ao que tudo indica, vários dos desencontros que cifram as culturas escolares podem ser considerados, em certa medida, no interior da tensão entre o circunscrito e o expandido. De um lado, um discurso canônico, ritualístico, ao mesmo tempo ordenador e normalizado, e, de outro, os imperativos dos meios de comunicação e das próprias dinâmicas da vida cotidiana. Ou seja, as práticas desenvolvidas em sala de aula estão conectadas com valores e referências instruídas por expectativas enciclopédicas, propedêuticas, nem sempre equacionadas aos requisitos dos alunos ou mesmo das dinâmicas sociais. Os media, em luta permanente para homogeneizar falas, completam aparentes faltas da escola, apresentando-se como um outro, pleno de sedução e capacidade de acenar com informações aparentemente suficientes para dispensar agências que lhes possam fazer concorrência, no mister de arrolar dados e narrar toda sorte de acontecimento. O cotidiano ${ }^{2}$, múltiplo e desfocado, amplo e difuso, considerando que as ruas, o trabalho, o lazer, o dia-a-dia, trazem consigo um saber comum, ao mesmo tempo facilitado e pleno de signos capazes de nortear, direcionar, acomodar sujeitos e grupos dentro de uma ordem que pretende sugerir ausência de controles, parece desejoso de expressar de forma quase exclusiva as dinâmicas sociais.

2. Ver: HELLER, Agnes. 0 quotidiano e a história. Rio de Janeiro: Paz e Terra, 1972; A theory of modernity (Uma teoria sobre modernidade). Cambridge: Blackwell Publishers, 1994; A crise dos paradigmas em Ciências Sociais e os desafios do século XXI. Rio de Janeiro: Contraponto, 1999.

\section{CONTRATOS E CONTRAVENÇÕES}

É ocioso dizer que a defesa de territórios visando à composição dos mapas perde, crescentemente, significado. Se a escola, os media e a rua possuem centros de valor que os singularizam, ao mesmo tempo tais instâncias (re)alimentam-se. Há conflitos e desacordos; porém, os residuais contaminam-se, não necessariamente em sequências complementares, de camadas acopladas como ao corpo a pele, mas percorrendo desvãos e barreiras próprias dos desenhos topográficos.

Se considerássemos o problema pela ótica da linguagem, diríamos que estamos no miolo do dialogismo, conforme os termos propostos por 
Mikhail Bakhtin. Isto é, os cruzamentos dos signos (e aqui poderíamos incluir a profusão de signos culturais) animam não apenas determinada série discursiva (verbal, por exemplo), mas cruzam várias séries (verbal e não-verbal; o texto literário que será levado ao cinema; a composição erudita inspiradora do romancista etc.). Ou seja, convivem dentro e entre as grandes codificações, as ruinarias, os estilhaçamentos, as contradições, os bifrontismos dos quais falava Walter Benjamin para caracterizar o barroco alemão ${ }^{3}$, e que animam as passagens de uma coisa a outra, garantindo, por fim, a circulação das linguagens e (re)arranjando os significados.

Escola, mídia e vida cotidiana são, ao mesmo tempo, permanências - pois definidoras de estruturas sistêmicas, por isso identificadas e mais ou menos reconhecidas socialmente - e tramas residuais ${ }^{4}$, linhas interconectadas, pontos cruzados, enfim, forças deslizantes buscando guarida em lugares inauditos, nos territórios vagos que os poderes instituídos pretendem delimitar.

Entende-se por que Marc Augé ${ }^{5}$ foi levado a elaborar o conceito de não-lugares - o lugar como espaço antropológico está marcado por identidades relacionais e históricas, ao contrário do não-lugar que é despido de tais características - para apreender as dinâmicas societárias caracterizadoras da sobremodernidade, termo que o francês coloca em lugar de pósmodernidade, movido pelo suposto de esta resultar de uma soma de traços aleatórios, enquanto aquela se constitui de três referenciais elaborados em torno da ideia do excesso. Em primeiro lugar, o excesso de acontecimentos, daí a percepção de que nada de novo ocorre: a inconsistência das coisas, a rapidez e a velocidade que impedem a reflexão e a estabilidade, promovendo um turbilhão informativo, uma sucessão de ocorrências, do que resulta, sob certo ângulo, a banalidade e mesmo a irrelevância dos acontecimentos. Em segundo lugar, o excesso dos espaços: estamos em todos os lugares e em lugar nenhum. Vemos os combates no Afeganistão, lemos acerca do avião que caiu na Mauritânia, acompanhamos os candidatos às eleições nos Estados Unidos se deslocando por cidadezinhas, hotéis, acampamentos de escoteiros. Ou podemos estar, fisicamente, em vários lugares (ou nãolugares), no movimento de quem passa por portos e aeroportos - espaços de ninguém e de multidões -, migrando, buscando outras esperanças, sonhos, nem sempre afeitos à cultura que nos formou, aos nossos referenciais identitários. Por último, o excesso de individualismo, a quebra da noção de grupo, de comunidade, de coletividade.

Ainda que o não-lugar revele o modo como homens e mulheres estão no mundo da alta modernidade, retornar ao lugar parece ser o desejo de todos, numa espécie de (re)encontro das identidades esgarçadas.

Entendido o caráter da análise feita por Marc Augé, em sua tentativa de plasmar certo espírito do tempo, é possível retomar a questão dos encontros e desencontros entre os media e a escola, situando-a como, de certo modo, paradoxal, visto que os dois parecem, muitas vezes, crer na fixidez dos lugares de produção discursiva.
3. BENJAMIN, Walter. Origem do drama barroco alemão. São Paulo: Brasiliense, 1984.

4. O conceito de tradição residual está em Raymond Williams. Ver WILLIAMS, Raymond. Culture (Cultura). Glasgow: William Collins, 1983.

5. AUGÉ, Marc. Não lugares: introdução a uma antropologia da supermodernidade. Lisboa: Bertrand Editora, 1994. 
comunicação \& educação • Ano XIV • Número 1 • jan/abr 2009

\section{ESTRANHAMENTOS E RESIDUAIS}

Talvez a escola conceba os meios de comunicação como adversários a serem combatidos, visto estarem dotados de discursos manipuladores, carregados de interesses comerciais, funcionando como pontas de lança da dominação e da tentativa de submeter as massas ao rigoroso regime da exploração de classe etc. Os media, por sua vez, costumam ver a escola como deslocada das demandas sociais, avessa a mudanças, adaptada a ritmos burocráticos que impedem a existência de uma educação de qualidade compromissada com os requisitos de um tempo que solicita agilidade de formação, adaptação aos apelos do mercado, sendo incapaz de responder aos desígnios do mundo globalizado. Por fim, não é difícil ao cotidiano deduzir ou acreditar que escola e meios de comunicação apresentam, ambos, limites, pois a primeira está distante dos saberes práticos, das intercorrências necessárias com o mundo da vida, enquanto os meios fazem resplandecer a luminosidade dos falsos brilhantes. Escola e media podem, também, cada um a seu jeito e segundo o seu modo de tratar os problemas, concluir que a vida cotidiana é o lugar do pensamento não elaborado, das falácias conceituais, do raciocínio tautológico, da superstição, do preconceito, do cenário tosco que se presta a reiterar determinações objetivas ou subjetivas nascidas de instituições socialmente mais reconhecidas como a sala de aula, o professor, a televisão, o jornalista.

Mantidas tais dicotomias ou até tricotomias, o assunto estaria resolvido; porém, quando movimentamos aquelas três esferas e as dispomos em perspectiva dialetizada, identificamos a constituição de processos representativos, simbólicos - traduzidos em disciplinas, currículos, telenovelas, conversas de bar -, carregados de resíduos e substratos, ora acentuados, ora minimizados, mas evidenciando afirmativas que buscam negações e negações plenamente afirmadas: a escola dando continuidade ao último capítulo da telenovela, a telenovela incorporando assuntos da educação formal ou não-formal, o cotidiano trazendo para si os dois lugares anteriores ou sendo por eles mimetizado.

A questão poderia ser resumida ao seguinte. O imperativo dos deslocamentos e viagens entre sistemas, processos, organizações, sujeitos, impõe ritmos e andamentos às dinâmicas sociais e culturais impeditivas da ideia segundo a qual os sentidos possuem autonomia de constituição. Colocado de outro modo, os sentidos não estão feitos, fazem-se nos deslocamentos, em contextos e situações, temporalidades e espacialidades, tencionando postos, pressupostos, subentendidos, inferências, relativizando a força dos emissores, requisitando e modalizando a presença dos receptores - aqui seria melhor considerá-los interlocutores ou co-enunciadores. Decorre deste ponto que a escola e os media, ambos contemplados de maneira mais evidente como lugares institucionais, têm dificuldades de acompanhar e, sob certas circunstâncias, compreender como funcionam os resíduos, em que direções são amarrados os fios de um tecido nem sempre identificado, mas claramente apreendido por diferentes sistemas de codificação. 
Comunicação e educação: passagens e deslocamentos • Adilson Citelli

O material selecionado para este número da revista Comunicação \& Educação procura, em diferentes níveis e circunstâncias, dar prosseguimento ao conjunto de preocupações aqui explicitados. Vamos a ele!

\section{ARTIGOS NACIONAIS}

O tema da relação entre pedagogia e hipermídia é tratado por Magda Salete Vicini, a partir da análise de obras de Joseph Beuys. Com isso, é aqui retomado o permanente debate acerca da produção artística enquanto instância comunicativa.

A preocupação com os jogos discursivos e contradiscursivos mobiliza o texto de Alexandre Almeida Barbalho, a partir de um instigante experiência levada a termo pelo programa $N o A r$, transmitido pela TV pública do Ceará e feito sob responsabilidade de grupos afeitos às classes populares.

Ângela Maria Rubel Fanini estuda o universo de representação do trabalho feminino a partir de textos produzidos por ouvintes paranaenses e transmitidos sob a forma das radionovelas.

As questões da socialização, da construção da identidade e das possibilidades integradoras que a linguagem musical ativa no universo dos jovens são tratadas no artigo de Maria da Graça Jacintho Setton.

O trabalho de Maria Helena Steffens de Castro é dedicado a pensar como a revisão histórica dos campos da comunicação e da educação pode ser rentabilizada a partir de documentos produzidos no domínio do discurso publicitário.

\section{ARTIGO INTERNACIONAL}

J. Ignacio Aguaded Gómez nos relata como a revista Comunicação \& Educação, no Brasil, e sua co-irmã espanhola Comunicar realizam há mais de uma década trabalhos muito próximos no que diz respeito à publicação de pesquisas, análises, reflexões, edição de materiais no âmbito educomunicativo.

\section{ARTIGO DE GESTÃO}

A partir de um projeto desenvolvido no âmbito da Gestão da Comunicação, Cristiane Batista Santana mostra como é possível produzir comunicação dialógica entre os museus e grupos, entidades e frequentadores.

\section{ENTREVISTA}

Em entrevista concedida pelo professor Pedro Bombonato, da USP, à co-editora da revista Comunicação \& Educação, professora Maria Cristina 
comunicação \& educação • Ano XIV • Número 1 • jan/abr 2009

Castilho Costa, ficamos sabendo como a Universidade de São Paulo implantou um importante programa de pré-iniciação científica dirigido a alunos do ensino médio da rede pública do Estado de São Paulo.

\section{CRÍTICA}

Especialista em novas tecnologias de produção musical, Gisela G. S. Castro nos mostra como o lançamento do álbum In Rainbows, da banda independente britânica Radiohead, provoca o debate acerca das temáticas da pirataria e dos direitos autorais na era digital.

\section{DEPOIMENTO}

No ano em que a União Brasileira de Cegos (UCB) celebrará os 200 anos do nascimento de Louis Braille, a revista Comunicação \& Educação colheu o depoimento de Dorina de Gouvêa Nowill, presidente emérita da Fundação Dorina Nowill para Cegos. Ficamos sabendo como a Fundação que ela dirige chega aos 62 anos cumprindo com o objetivo de inclusão social de deficientes visuais.

\section{EXPERIÊNCIA}

Em seu artigo, Vanessa Freitag descreve e analisa as memórias de infância relatadas por professoras de Artes Visuais da Casa de Cultura de Santa Maria-RS, mostrando os nexos entre experiências vividas e processos de trabalho criativos implantados pelas docentes.

\section{POESIA}

Adilson Citelli e Cristine Vargas selecionaram alguns textos de Adélia Prado com o intuito de mostrar como uma série de temas prosaicos, cotidianos, vão ganhando força e inventividade na obra da poeta.

\section{SERVIÇOS}

A seção apresenta duas atividades de entretenimento para professores e alunos. O Projeto Escola no Cinema, concebido pelo Circuito Espaço de Cinema, e o Clube do Professor, sessões exclusivas para professores, todos os sábados, nos cinemas da rede Unibanco Arteplex e Espaço Unibanco de Cinema. 
Comunicação e educação: passagens e deslocamentos • Adilson Citelli

\section{VIDEOGRAFIA}

Maria Ignês Carlos Magno indica as possibilidades de trabalho que se abrem à escola com filmes como Fahrenheit 451, de François Truffaut (1966), e Escritores da Liberdade, de Richard LaGravenese (1995).

\section{BOLETIM BIBLIOGRÁFICO}

As subseções de Bibliografia sobre telenovela brasileira e Bibliografia sobre comunicação e educação apresentam livros, teses e dissertações sobre as respectivas temáticas. Endereços úteis na internet podem contribuir para incrementar as tarefas cotidianas dos professores.

\section{ATIVIDADES EM SALA DE AULA}

Ruth Ribas Itacarambi propõe projetos pedagógicos a serem desenvolvidos em sala de aula com alunos do ensino fundamental e médio, bem como de nível superior, utilizando artigos publicados neste número. 


\section{๔ृ}
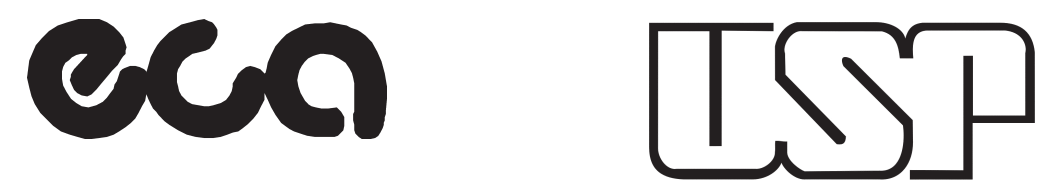

\section{ESPECIALIZAÇÃO LATO SENSU Gestão da Comunicação}

gestor da comunicação planeja e executa projetos de comunicação em empresas privadas, instituições públicas ou movimentos comunitários, nas áreas educacional, empresarial ou artístico-cultural.

- Capacitação do aluno para elaborar, implantar, avaliar e reestruturar projetos de comunicação/cultura.

- Integração teórico-prática da área de comunicação com o mercado de trabalho.

- Formação humanística e profissional sólidas, baseadas na inter-relação comunicação/cultura/artes.

- Qualificação do profissional, preparando-o para compreender o mercado emergente, em constante transformação, e agir sobre ele.
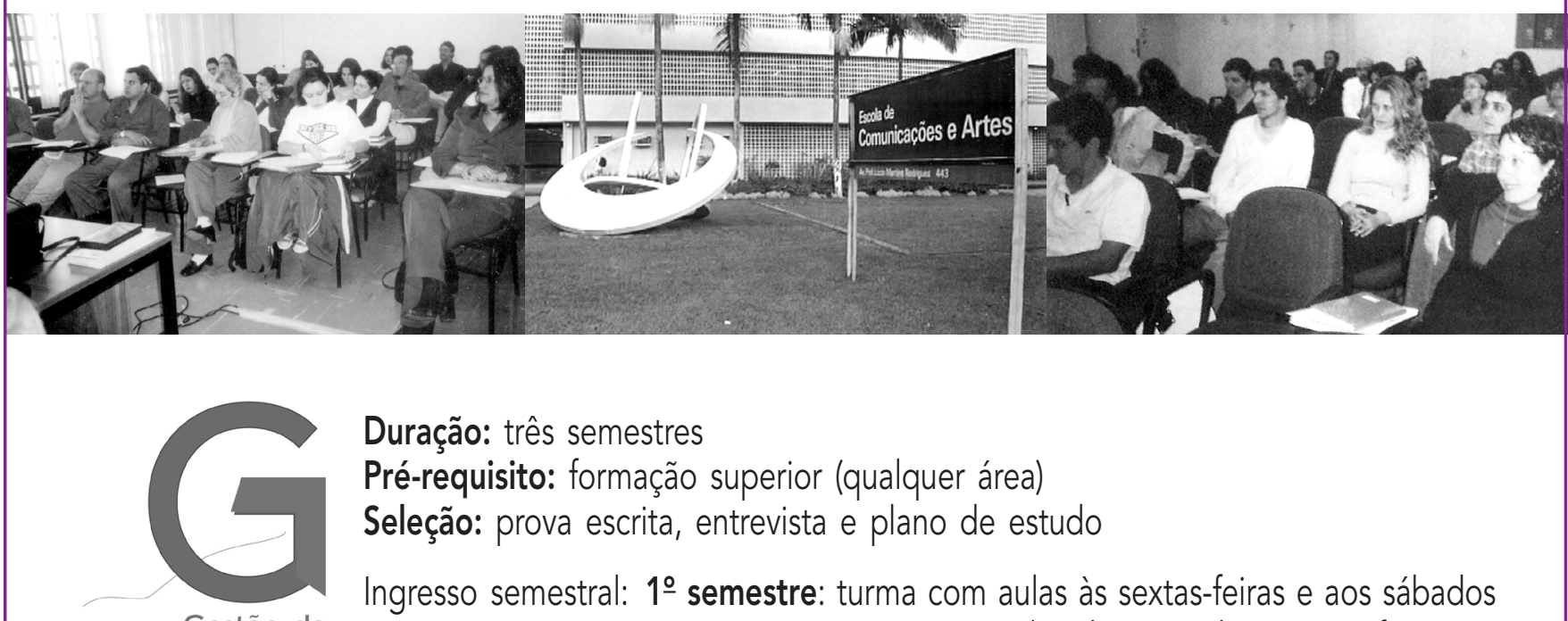

Gestão da Comunicação

Duração: três semestres

Pré-requisito: formação superior (qualquer área)

Seleção: prova escrita, entrevista e plano de estudo

Ingresso semestral: 1ำ semestre: turma com aulas às sextas-feiras e aos sábados

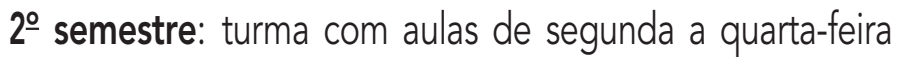
CCA - ECA - USP

Informações: ECA/USP: 3091-4063/4341/4326 - e-mail: gestcom@edu.usp.br www.eca.usp.br/gestcom 